\title{
Pyruvate carboxylase deficiency, benign type
}

INSERM

\section{Source}

INSERM. (1999). Orphanet: an online rare disease and orphan drug data base. Pyruvate carboxylase deficiency, benign type. ORPHA:353320

Benign pyruvate carboxylase (PC) deficiency (Type $C$ ) is a rare, very mild form of PC deficiency characterized by episodic metabolic acidosis and normal or mildly delayed neurological development. 